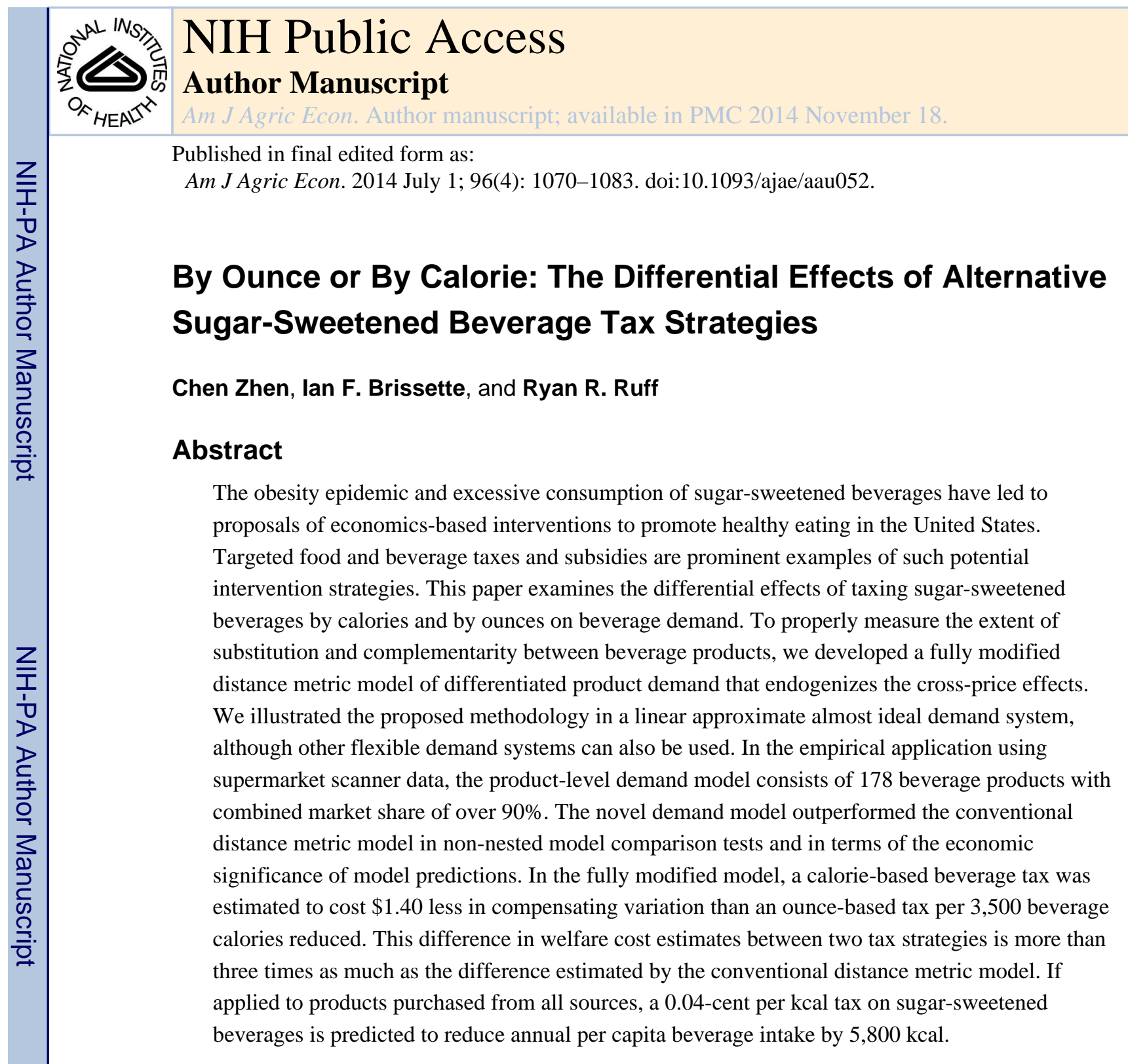

\title{
Keywords
}

obesity; sugar-sweetened beverage tax; distance metric demand model

\begin{abstract}
With obesity rates remaining at epidemic levels in the United States (Ogden et al. 2012) and obesity-related noncommunicable diseases inflicting large economic burdens on society, public policy makers have given increased consideration to policies with potential to promote healthy eating. To address the imbalance between dietary energy intake and expenditure that underlies excess body weight, policy proposals have targeted calorie-dense foods with minimal nutritional value. Sugar-sweetened beverages (SSBs), which include carbonated soft drinks (CSDs), fruit drinks, and sports and energy drinks, accounted for an
\end{abstract}

\footnotetext{
${ }^{8}$ The conditions are: first-stage beverage demand is homogenous of degree zero in $p b h t$, and $y h t$; demand is non-negative; group expenditure on beverages is less than income; and the Slutsky substitution matrix is symmetric and negative semidefinite (see Theorem 2 in LaFrance and Hanemann 1989).

${ }^{10}$ The complete SAS and STATA codes for estimation and simulation are posted online as supplementary data.
} 
estimated 7\% of total energy intake for an average American in 2005- 2006 (National Cancer Institute 2010) and are a significant risk factor for obesity and obesity-related health complications (e.g., Schulze et al. 2004). Public health advocates and some policy makers have targeted SSBs for potential policy interventions.

Policy interventions aimed at reducing SSB intake in the United States have focused on two factors affecting demand: accessibility and affordability. Examples of access restrictions include state or local bans on regular or all carbonated soft drinks in schools (Huang and Kiesel 2012), policies that limit the availability of SSBs at meetings and events (New York City Department of Health, 2013), and New York City's 2012 policy proposal restricting the sale of SSBs to containers no more than 16 ounces in size in food service establishments.

Taxes on SSBs represent the most common policy aimed at making SSBs less affordable. In 2012, eight U.S. states and two cities filed SSB tax legislation (Rudd Center for Food Policy \& Obesity 2013). However, no state or city has enacted an excise tax that approaches the magnitudes required to significantly alter consumer demand for SSBs. One reason a significant excise tax on SSBs has not passed is the concerns about the health and economic implications of these taxes. Taxing SSBs may have the unintended consequence of causing consumers to substitute other calorie-dense but untaxed beverages and foods (e.g., Fletcher, Frisvold, and Tefft 2010). With regard to economic impact, assuming consumers are fully rational, an SSB tax could reduce consumer surplus in the short run before any potential long-term health benefits and savings in medical costs are realized.

An optimal taxation strategy would seek to achieve a given level of reduction in SSB calories at the lowest cost to consumers. The majority of existing SSB excise tax proposals in the United States specify a per-volume tax (i.e., cent per ounce). This strategy overlooks that a large variety of SSB products on the market are differentiated by caloric content, among other product attributes. For example, the mean energy content for the 91 top-selling SSB products in New York State markets between 2007 and 2011 was $91.6 \mathrm{kcal} / 8$-ounce ${ }^{1}$ serving, with a standard deviation of $33.7 .^{2}$ Ceteris paribus, a tax levied based on the caloric density of SSB products may be more efficient in reducing SSB calories than an ouncebased tax.

The objective of this study was to simulate the gain in efficiency from a calorie-based tax scheme compared with an ounce-based one using demand parameters estimated from a product-level demand model. Our demand model encompasses 178 beverage products accounting for $95 \%$ of all nonalcoholic beverages (excluding milk, liquid coffee and tea, and soft drink powder) in volume across four New York markets. We measured the efficiency of an SSB tax by compensating variation (CV) per 3,500 $\mathrm{kcal}^{3}$ beverage energy reduced. The extant literature on U.S. SSB demand (Zhen et al. 2011, 2014; Dharmasena and Capps 2012; Lin et al. 2011; Finkelstein et al. 2013) simulates the effects of ounce-based SSB taxes using parameters estimated from category-level demand models, where product-level substitutions

\footnotetext{
$1_{1 \mathrm{kcal}}=4.184 \mathrm{~kJ} ; 1 \mathrm{fl} \mathrm{oz}=29.574 \mathrm{ml}$.

2 Authors' calculation based on Nielsen ScanTrack sales data and calorie information collected from manufacturers' websites.

$33,500 \mathrm{kcal}$ per pound of body weight is a widely used rule for back-of-the-envelope calculations of weight gain/loss resulting from changes in energy intake.
} 
are not explicitly modeled. Because a calorie-based SSB tax changes the relative prices of SSB products, estimating product-level substitutions is essential. By allowing for productlevel substitutions, this study fills an important gap in the literature on targeted food and beverage taxes.

We also contribute to the methodology literature on differentiated product demand by introducing a novel approach to incorporating product heterogeneity into the estimated cross-price effects. Our demand model builds on the distance metric (DM) approach of Pinkse, Slade, and Brett (2002), which specifies cross-price effects between differentiated products as functions of their closeness in the attribute space. We modify the conventional DM model by endogenizing the cross-price effect between two rival products using their budget shares. In the application to New York beverage demand, the new model, which we call the fully modified DM (FMDM) model, outperforms the conventional model in both statistical and economic significance. Compared with the FMDM model, a conventional DM model underestimates the degree of product substitution and, therefore, overestimates the net effect of a beverage tax on beverage calories purchased. Simulations based on demand estimates from the FMDM model suggest that a calorie-based SSB tax would cost $\$ 1.40$ less in consumer surplus loss per 3,500 kcal of beverage energy reduced than an ounce-based tax. The conventional DM model underestimates the savings in consumer surplus, attainable by switching from an ounce-based tax to a calorie-based one, by more than a factor of three.

\section{DIMENSION REDUCTION METHODS}

For most food and beverage categories on the U.S. market, products within the same category are differentiated by various product attributes. In an unrestricted product-level demand system, there are $n^{2}$ price coefficients, where $n$ is the number of products. Imposing symmetry, homogeneity, and adding-up restrictions reduces the number of parameters to $n(n$ -1) 2. Despite this reduction, the dimension of the parameter space is still too large to estimate for any system with more than a few dozen products.

Three approaches have been used to reduce the dimension of the parameter space. First, assuming the consumer chooses at most one unit of a product in each shopping trip, a family of discrete-choice models is available for modeling product substitutions within a category (e.g., Nevo 2001). However, this approach does not identify consumer choices across categories. The second approach uses multistage budgeting to limit the number of products or product categories the consumer has to choose from at each stage of the budget decision (e.g., Ellison et al. 1997). Although this approach no longer restricts the consumer to one unit of a product as in a discrete-choice model, it restricts substitution or complementarity patterns between products from different categories. Because there is often more than one way to categorize products, the estimated product-level cross-price effects depend on the chosen categorization. When there are a large number of products, one may need several budgeting stages to keep the number of goods tractable at each stage. The third approach uses DM models to solve the dimensionality problem by casting the $n^{2}$-dimensional price effects into the lower-dimensional product attribute space. In contrast to discrete-choice models, a DM model allows consumers to purchase any number of products within the budget constraint. Unlike the multistage budgeting approach, the cross-price effects in DM 
models are not determined by one and only one categorization scheme but by multiple product attributes. Most DM models are linear in parameters-a desirable property in light of recent findings of numerical difficulties in estimating some nonlinear discrete-choice models (Dubé, Fox, and Su 2012; Knittel and Metaxoglou 2014). Nevertheless, a weakness of DM models is that the cross-price effects are limited to the attributes specified by the researcher. Therefore, it is important to use a comprehensive list of product attributes to reduce this bias.

\section{THE FMDM ALMOST IDEAL DEMAND SYSTEM}

The linear approximate version of Deaton and Muellbauer's (1980) almost ideal demand system (AIDS) is the most popular functional form adopted in DM models. Assuming weak separability between beverage products and the numéraire good, we can use two-stage budgeting to characterize consumer preferences for beverage products. In the first stage, the consumer allocates expenditures between the numéraire good and the beverage group. In the second stage, the consumer chooses beverage products conditional on total beverage expenditure. We used the following linear approximate AIDS to represent the conditional demand in the second stage ${ }^{4}$ :

$$
w_{i h t}=\alpha_{i h t}+\gamma_{i i} \ln p_{i h t}+\sum_{j \neq i} \gamma_{i j h t} \ln p_{j h t}+\beta_{i} \ln \left(x_{h t} / p_{b h t}\right),
$$

where $w_{i n h t}$ is the budget share of product $i$ in market $h$ and period $t ; \alpha_{i h t}$ is an intercept; $p_{j h t}$ is the price of product $j$ normalized to one at $j$ 's sample mean (Moschini 1995); $x_{h t}$ is per

capita total beverage expenditure; In $p_{b h t} \equiv \sum_{j \in N_{h t}} w_{j h t} l n p_{j h t}$ is the group price index for beverage products and subscript $b$ stands for beverage group; $N_{h t}$ represents the set of $n_{h t}$ beverage products available in market $h$ and period $t$; and $\gamma$ and $\beta$ are parameters.

The DM approach specifies the cross-price effect between two products as functions of their closeness in attribute space. The key difference between the FMDM model and a conventional DM model lies in the specification of the cross-price effect. The FMDM crossprice coefficient $\gamma_{i j h t}$ is written as

$$
\gamma_{i j h t}=\sum_{m=1}^{M} d_{m} w_{i h t} w_{m i j h t}^{*}, \quad i \neq j
$$

where $d_{m}$ is the parameter associated with the $m$ th discrete product attribute (e.g., flavor), $M$ is the number of discrete attributes, $w^{*}{ }_{m i j h t}=w_{j n t} \kappa_{m j j} / \omega_{m i h t}, \kappa_{m j j}$ is a binary variable equal to 1 if products $i$ and $J(j \neq i)$ share the same level/description in the $m$ th attribute (e.g., both cola products), and 0 otherwise (including the case $\kappa_{m i i}=0$ ), and

$\omega_{\text {miht }}=w_{i h t}+\sum_{k e N_{h t}} w_{k h t} \kappa_{\text {mik }}{ }^{5}$ We included $w_{\text {iht }}$ in $\omega_{\text {miht }}$ to meet the symmetry condition $\gamma_{i j h t}=\gamma_{j i h t}$. Instead of $n_{h t}-1$ cross prices in a standard linear approximate AIDS, there $M$

\footnotetext{
${ }^{4}$ Other flexible functional forms may also be used. One such candidate is the linear approximate Exact Affine Stone Index demand system of Lewbel and Pendakur (2009).
} 
cross-price terms, $\sum_{j \neq i} w_{i h t} w_{m i j h t}^{*} \ln p_{j h t}$, in the budget share equation of an FMDM model. Because budget shares appear on both sides of equation (1), we accounted for this simultaneity in the formulation of elasticities and in econometric estimation.

For most consumer product markets, observed differences in product attributes and market conditions cannot explain all demand fluctuations. For example, the cross-price relationship between Coke and Pepsi may be different from their cross-price relationships with a privatelabel cola product because of differences in brand equity and other less quantifiable attributes (e.g., taste), even though all three are cola products. The FMDM model uses budget shares $w_{i h t}$ and $w_{j h t}$, which are outcomes of both observed and unobserved drivers of demand, to quantify this heterogeneity in cross-price effects. The conventional DM model does not have this feature and specifies the cross-price coefficient as $\gamma_{i j h t}=\sum_{m=1}^{M} d_{m} \kappa_{m i j}^{*}$, where $\kappa_{m i j}^{*}=\kappa_{m i j} /\left(1+\sum \kappa_{m i k}\right) \cdot 6$

\section{FMDM Elasticities}

In this section, we provide the conditional and unconditional price elasticities and expenditure elasticities for the FMDM model. Derivation details are available in the online appendix. For brevity of notation, we dropped the market and time subscripts $h$ and $t$ from the FMDM elasticities. In matrix notation, the Marshallian price elasticities conditional on total beverage expenditure are

$$
\mathrm{H}=\left\{I-\sum_{m=1}^{M} B_{m}-\sum_{m=1}^{M} D_{m}+\sum_{m=1}^{M} C_{m} F_{m}+U V\right\}^{-1}(A+I)-I .
$$

The matrix elements in equation (3) are $\mathrm{H}_{i j}=\eta_{i j}$ in $\mathrm{H}(n \times n$ matrix $)$, where $\eta_{i j}$ is the conditional Marshallian elasticity for product $i$ with respect to price of $j ; A_{i j}=-\delta_{i j}+\gamma_{i j} / w_{i}-$ $\beta_{i} w_{j}$ in $A$ ( $n \times n$ matrix), where $\delta_{i j}=1$ for $i=j$, and 0 otherwise;

$B_{m i i}=\sum_{r} d_{m} w_{m i r}^{*} \ln p_{r} \sum_{k} w_{m i k}^{*}$ in $B_{m}(n \times n$ diagonal matrix $) ; D_{m i j}=d_{m} w^{*}{ }_{m i j}$ in $p_{j}$ in $D_{m}$ $(n \times n$ matrix $) C_{m i i}=\sum_{r} d_{m} w_{m i r}^{*} l n p_{r}$ in $(n \times n$ diagonal matrix $) ; F_{m i j}=w *{ }_{m i j}$ in $F_{m}(n \times n$ matrix $) ; U_{i}=\beta_{i} / w_{i}$ in $U(n \times 1$ vector $) ; V_{j}=w_{j}$ In $P_{j}$ in $V(1 \times n$ vector $)$; and $I$ is a $n \times n$ identity matrix. The FMDM expenditure elasticities are

$$
\mathrm{E}=\left\{I-\sum_{m=1}^{M} B_{m}-\sum_{m=1}^{M} D_{m}+\sum_{m=1}^{M} C_{m} F_{m}+U V\right\}^{-1} U+t
$$

\footnotetext{
${ }^{5}$ We also developed a simpler specification of the cross-price coefficient: $\gamma_{i j h t}=\sum_{m=1}^{M} d_{m} w_{i h t} w_{j h t} \kappa_{m i j \text {, which was not }}$ normalized by $\omega_{\text {miht }}$. However, simulation based on this alternative model suggested that an ounce-based SSB tax would increase total beverage calories in some markets and periods. Although an unintended consequence of this magnitude is not impossible, it is less plausible given that all existing studies of SSB demand predict a net decrease in beverage calories following a volume-based SSB tax. Therefore, we rejected this alternative specification in favor of equation (2).

${ }^{6}$ The empirical findings were qualitatively the same when the cross-price effect in the conventional DM model was not normalized by $\left(1+\sum \kappa_{m i k}\right)$, i.e. $\left(1+\sum \kappa_{m i k}\right)$, i.e. $\gamma_{i j h t}=\sum_{m=1}^{M} d_{m} \kappa_{m i j}$.
} 
where, in addition to matrices defined in equation (3), the matrix elements are $E_{i}=\varepsilon_{i}$ in $\mathrm{E}$ (n $\times 1$ vector) with $\varepsilon_{i}$ being the expenditure elasticity for product $i$, and $t$ is an $n \times 1$ vector of ones. Without the ones. Without the $B_{m}, C_{m}, D_{m}$, and $F_{m}$ terms, equations (3) and (4) become the price and expenditure elasticities, respectively, for a conventional DM model with a Stone group price index (Green and Alston, 1990). These additional terms account for the effects of endogenous budget shares in $\gamma_{i j h t}$ on cross-price elasticities.

To derive unconditional price elasticities, note that a change in price of $j$ affects demand for $i$ in two ways: first through the price effect conditional on total beverage expenditure and second through an expenditure effect. This can be expressed as

$$
\eta_{i j}^{i i}=\eta_{i j}+\varepsilon_{i}\left(\partial \ln x / \partial \ln p_{j}\right)
$$

where the superscript $u$ denotes unconditional price elasticity. The last term in equation (5) can be decomposed as follows:

$$
\begin{aligned}
\frac{\partial \ln x}{\partial \ln p_{j}}=\frac{\partial \ln \left(p_{b} q_{b}\right)}{\partial \ln p_{j}}=\frac{\partial \ln \left(p_{b} q_{b}\right)}{\partial \ln p_{b}} \frac{\partial \ln p_{b}}{\partial \ln p_{j}} & =\left(1+e_{b b}\right)\left\{w_{j}+\sum_{r e N} w_{r} \ln p_{r}\left[\frac{\partial \ln w_{r}}{\partial \ln p_{j}}+\frac{\partial \ln w_{r}}{\partial \ln x} \frac{\partial \ln x}{\partial \ln p_{j}}\right]\right\} \\
& =\left(1+e_{b b}\right)\left\{w_{j}+\sum_{r e N} w_{r} \ln p_{r}\left[\eta_{r j}+\delta_{r j}+\left(\varepsilon_{r}-1\right) \frac{\partial \ln x}{\partial \ln p_{j}}\right]\right\}
\end{aligned}
$$

where $q_{b}$ is total beverage quantity, and $e_{b b}$ is overall price elasticity for the beverage group in the first stage of the two-stage budgeting. The $w_{j}$ term in curly brackets in equation (6) measures the first-order effect of a change in $p_{j}$ on group price $p_{b}$, while the remaining terms in curly brackets sum up the second-order effect of changing $p_{j}$ on $p_{b}$ through budget share changes. In matrix notation, equation (6) can be expressed as

$$
\mathrm{E}_{x p}=\left(1-e_{b b}\right)\left\lfloor W+V(\mathrm{H}+I)+V(\mathrm{E}-t) \mathrm{E}_{x p}\right\rfloor,
$$

where $E_{x p}$ is $l \times n$ with the $j$ th element equal to $\partial \ln x \partial \ln p_{j}$ and $W_{j}=w_{j}$ in $W(1 \times n$ vector $)$. Solving (7) for $\mathrm{E}_{\mathrm{xp}}$ gives

$$
\mathrm{E}_{x p}=\frac{\left(1+e_{b b}\right)[W+V(\mathrm{H}+I)]}{1-\left(1+e_{b b}\right) V(\mathrm{E}-t)} .
$$

Finally, the unconditional price elasticities in matrix form are

$$
\mathrm{H}^{u}=\mathrm{H}+\mathrm{E} \times \mathrm{E}_{x p}
$$

where the $n \times n$ matrix $\mathrm{H}^{\mathrm{u}}$ has $\eta_{i j}^{u}$ as its elements.

\section{The Quasi-FMDM Model}

The FMDM elasticity formulas are more complicated than those of a conventional DM model. To evaluate the merit of this added sophistication, we developed a quasi-FMDM model that is an approximation to the FMDM but uses the simpler elasticities of a conventional DM model. The cross-price effect in the quasi-FMDM model is specified as 


$$
\gamma_{i j h t}=\sum_{m=1}^{M} d_{m} w_{i 0} w_{0 m i j h t}^{*}
$$

, where

$$
w_{0 m i j h t}^{*}=w_{j 0} \mathrm{~K}_{m i j} / \omega_{0 m i h t}, \omega_{0 m i h t}=w_{i 0}+\sum_{k \in N_{h t}} w_{k 0} \mathrm{~K}_{m i k}
$$

, and $w_{j 0}$ is base share defined as the sample mean budget share of product $j$. Because the base shares are constants, elasticities for the quasi-FMDM model simplify to those of a conventional DM model.

\section{DATA AND VARIABLES}

Nielsen ScanTrack scanner data provide nonalcoholic beverage sales data for the Albany, Buffalo, New York City, and Syracuse Nielsen markets. Each market consists of a cluster of counties and is not confined by city or state boundaries. ${ }^{7}$ For example, the Albany market includes not only counties in New York but also counties in Massachusetts and Vermont, the Buffalo market incorporates counties in Pennsylvania, and the New York City market covers parts of Connecticut and New Jersey. The scanner data are collected from a sample of supermarkets with annual sales of at least $\$ 2$ million and projected to the market level by Nielsen for this store format. Data on milk, liquid tea and coffee, and soft drink powder and sales at convenience stores, drug stores, club stores, and mass merchandisers were not available to the authors and are not included in the model. Sales data were recorded at the Universal Product Code (UPC) level and cover 64 four-week periods beginning on January 28, 2007, and ending on December 24, 2011. Scanner data included UPC-specific information such as package and container sizes, product module, brand, and others. The authors collected information on the caloric content of products from manufacturers' websites and linked that information with the sales data. To limit the number of products in the demand model and preserve as much product differentiation as possible, we created unique products by aggregating similar UPC items based on brand and product module. For example, Coke, Diet Coke, Caffeine-Free Coke, and Caffeine-Free Diet Coke are four unique products in our demand model, but 2-liter Coke and Coke in 12-ounce cans are considered the same product.

\section{Descriptive Statistics}

The beverage market is characterized by a large number of products with small individual market shares. In 2007-2011, 18 products had market shares of $1 \%$ or above and collectively represented $43 \%$ of the beverage market in dollar sales. Lowering the market share threshold to $0.5 \%$ increases the number of products to 45 and combined market share

\footnotetext{
${ }^{7}$ The scanner data exclude sales taxes. The level of sales taxes levied on soft drinks ranged from $0 \%$ in Massachusetts and Vermont to $7 \%$ in New Jersey and did not change during the sample period (Bridging the Gap, 2014). Therefore, differences in state sales tax rates are absorbed into the product-market specific fixed effects in the demand model (see equation [12]).
} 
to $61 \%$. To capture as much of the market in the demand model as feasible, we included all products whose total dollar sales over the 2007-2011 period represented $0.1 \%$ or more of the beverage markets. The resulting data set for estimation yielded an unbalanced panel of 43,087 observations across 178 products, accounting for $92 \%$ of total dollar sales in the four markets.

Table 1 presents per capita annual volume, energy, and expenditures for the 178 products by product category. In these markets, CSDs account for the majority of beverage energy $(51.5 \%)$ and a smaller share of total beverage expenditures (24.1\%). Because the ScanTrack data we have does not account for sales at retail outlets other than supermarkets, it is useful to examine supermarket shares within total retail sales. Zhen et al. (2014) report estimates of national average household beverage purchases by category based on the 2006 Nielsen Homescan - household-based scanner data on food purchases from all retail outlets. Assuming comparable sales patterns between 2006 and 2007-2011 and between New York and the rest of the country, a comparison of table 1 with purchase quantities in Zhen et al. (2014) indicates that, in terms of volume shares, ScanTrack supermarkets accounted for about $64 \%$ of regular and diet CSD sales, $46 \%$ of sports and energy drink sales, $73 \%$ of $100 \%$ juice sales, $39 \%$ of fruit drink sales, and $76 \%$ of bottled water sales. The lower shares of sports and energy drinks and fruit drinks may be attributed, in part, to sales data on soft drink powder being unavailable to this study, while Zhen et al.'s data set included powdered drinks.

\section{Attribute Variables}

We specified seven discrete attributes with potential relevance to determining cross-price effects. The variable brand family takes 92 distinct values associated with 92 brand families. For example, Coke is a brand family that encompasses regular and Diet Coke and CaffeineFree Coke. It is reasonable to expect products under the same brand family to be closer substitutes than products under different brand families. The variable name brand identifies any beverage product that is not a private-label product. The variable major product identifies products that had a market share of $0.5 \%$ or higher over the 2007-2011 period. Because these products are likely to receive larger shelf space and be available in more stores, they may be closer substitutes to one another than to products having much smaller market shares. The variable product category classifies the 178 products into six product categories (see table 1) consistent with the categorization scheme used in previous categorylevel beverage demand models (e.g., Zhen et al. 2011; Dharmasena and Capps 2012). The variable energy category distinguishes regular CSDs, full-calorie sports and energy drinks, and full-calorie fruit drinks from low-calorie (defined as $\leq 10 \mathrm{kcal} / 8$-ounce serving) versions of these sweetened beverages and bottled water. The rationale is that consumers might perceive soft drinks with more similar energy content to be more substitutable. The variable caffeine indicates the presence of caffeine, which is found in some CSDs and all energy drinks. The variable flavor takes nine distinct values: cola, root beer, citrus for CSDs/fruit drinks/sports drinks, citrus for $100 \%$ juice, ginger ale, pepper, seltzer, apple, and cranberry. 


\section{EMPIRICAL SPECIFICATION AND RESULTS}

We used the first-stage demand to obtain an estimate of the overall beverage price elasticity $\left(e_{b b}\right)$ and to calculate the welfare effects of SSB taxes. LaFrance and Hanemann (1989) showed that under fairly mild conditions an incomplete demand system provides the exact and correct measures of welfare changes.

$$
w_{b h t}=a_{b h t}+r_{b b} \ln p_{b h t}+r_{b o} \ln p_{o h t}+b_{b} \ln \left(y_{h t} / p_{h t}\right) \text {, }
$$

where $w_{b h t}$ is the budget share of nonalcoholic beverages in market $h$ and period $t ; a_{b h t}$ is an intercept; $P_{o h t}$ is the price index for the numéraire good and subscript $o$ stands for other goods and services; ${ }^{9} y_{h t}$ is per capita income; $p_{h t}$ is a cost-of-living index defined as $\ln p_{h t}=$ $a_{0}+a_{b h t} \ln p_{b h t}+a_{o h t} \ln p_{\text {oht }}+0.5 r\left(\ln p_{b h t}\right)^{2}+r_{b o} \ln p_{b h t} \ln p_{o h t}+0.5 r_{o o}\left(\ln p_{o h t}\right)^{2}$; and $r$ and $b$ are parameters. To account for market and time fixed effects, the intercept term $a_{b h t}$ is augmented as follows:

$$
a_{b h t}=a_{b 0}+\sum_{j=2}^{4} c_{b j} \times m k_{j h t}+\sum_{k=2}^{13} g_{b k} \times q w_{k h t}+\sum_{l=08}^{11} v_{b l} \times r_{l h t},
$$

where $m k_{j h t}, q w_{k h t}$, and $y r_{l h t}$ are binary indicator variables for market $j$, the $k$ th fourweek period (out of a total of 13) of a year, and year $l$, respectively; and $a_{b 0} c_{b j}, g_{b k}$, and $v_{b l}$ are coefficients.

The Stone price indices $p_{b h t}$ and $p_{\text {oht }}$ may be endogenous because they use current budget shares as weights. We used the loglinear analogue of Laspeyres prices (Moschini 1995) for the beverage group and the numéraire good as instruments. For example, the instrument for $\ln p_{b h t}$ was calculated as $\ln \widetilde{p}_{b h t} \equiv \sum_{j \in N_{h t}} w_{j 0} \ln p_{j h t}$. The budget share equation (10) and the two instrumental variable equations for $\ln p_{b h t}$ and $\ln p_{\text {oht }}$ were estimated jointly using full information maximum likelihood (FIML). The parameter estimates and their standard errors are reported in table 2.

The Durbin-Wu-Hausman (Durbin 1954; Wu 1973; Hausman 1978) test for the exogeneity of $p_{b h t}$ and $p_{\text {oht }}$ produced a test statistic of $30.14(p=0.115, d f=22)$. The mean overall beverage price elasticity is -0.967 and -0.658 with and without correction for simultaneity bias, respectively. Although exogeneity was not rejected at conventional significance levels, the magnitude of difference in elasticity point estimates seems to be economically important. Therefore, the subsequent analyses are based on estimates of the first-stage demand that corrected for the simultaneity bias.

\section{DM Model Estimation}

To account for demand heterogeneity across products, markets, seasons, and over time, we augmented the intercept of equation (1) as follows:

\footnotetext{
${ }^{9}$ Price index for the numéraire good was obtained by solving $\ln C P I_{h t}=w_{b h t} \ln p_{b h t}+w_{o h t} \ln p_{o h t}$ for $p_{o h t}$, where $C P I$ is the consumer price index for all goods and services.
} 


$$
\alpha_{i h t}=\phi_{i h}+\sum_{c=1}^{178} \varphi_{c} \times z_{c i} \times t e m p_{h t}+\sum_{c=1}^{178} \theta_{c} \times z_{c i} \times \operatorname{trend}_{h t},
$$

where $\varphi_{i h}$ is the constant for product $i$ in market $h ; z_{c i}$ is an indicator variable for product $c$, equal to 1 if $c=i$ and 0 is the temperature for market $h$ and period $t$; trend $_{h t}$ is a linear time trend; and, and $\varphi, \phi$, and $\Theta$ are parameters. By including product-specific market, seasonal, and trend effects, equation (12) controls for a wide range of heterogeneities that, if unaccounted for, may result in biased estimates of price coefficients.

The budget share equation (1) cannot be estimated as a system of $n_{h t}$ equations because $n_{h t}$ - the number of products in market $h$ and period $t$-is too large and varies across markets and over time. Consistent with previous DM studies, we estimated equation (1) as a single equation. Some studies restricted the own-price coefficients $\gamma_{i i}$ and expenditure coefficients $\beta_{i}$ to be functions of product attributes (e.g., Pinkse and Slade 2004; Rojas and Peterson 2008; Bonanno 2013). We did not impose these restrictions to build in sufficient flexibility for the estimated own-price and expenditure effects. In the estimation equation, we interacted $\log$ own price $\ln p_{i h t}$ and $\log$ real group expenditure $\ln \left(x_{h t} / p_{b h t}\right)$ with product dummies $z_{c i}$ to obtain product-specific estimates for $\gamma_{i i}$ and $\beta_{i}$.

Symmetry is satisfied in DM models. Homogeneity may be imposed in estimation by normalizing product prices by a numéraire beverage, although we did not follow this approach. Adding-up is more difficult, if not impossible, to impose during estimation because the number of products changes across $h$ and $t$. To ensure that the elasticity

estimates are consistent with economic theory, we imposed the Engel $\left(\sum_{i \in N_{h t}} w_{i h t} \varepsilon_{i h t}=1\right)$, Cournot $\left(w_{j}+\sum_{i \in N_{h t}} w_{i h t} \eta_{i j h t}=0\right)$, and Euler $\left(\varepsilon_{i h t}+\sum_{j \in N_{h t}} \eta_{i j h t}=0\right)$ aggregations on the DM models after estimation. ${ }^{11}$ This is in line with the approach in the literature on censored demand system estimation that also has difficulty imposing adding-up in estimation (e.g., Yen, Lin, and Smallwood 2003; Sam and Zheng 2010).

We estimated the conventional DM, quasi-DM, and FMDM models using fixed-effects (FE) two-stage least squares (2SLS), where the product-market-specific intercept $\varphi_{i h}$ is the fixed effect. Because group expenditure can be endogenous (LaFrance 1991), we used $\ln \left(x_{h t} / p_{b h t}\right)$ to instrument $\ln \left(x_{h t} / p_{b h t}\right)$, where $x_{h t}$ is the mean group expenditure for the same period in other years. In addition, we used the cross-price terms of the conventional DM and quasiFMDM to instrument the endogenous cross-price terms of the FMDM model. Table 3 summarizes the endogenous regressors and excluded instruments for each DM model.

\section{DM Model Estimation Results}

Table 4 presents the DM estimation results. For brevity, the coefficient estimates for own prices and demand shifters in equation (12) are not displayed. The generalized $R^{2}$ of Pesaran

\footnotetext{
${ }^{11}$ We used these restrictions to recover the own- and cross-price elasticities of the $n$th product in each market and period. Nevertheless, all empirical results remained qualitatively unchanged when these restrictions were not imposed.
} 
and Smith (1994) is used as a goodness-of-fit measure because the standard $R^{2}$ is not a valid model selection criterion for instrumental variable regressions. A comparison of the generalized $R^{2}$ suggests that the FMDM and quasi-FMDM models fit the data equally well and outperform the conventional DM model. The equivalence of FMDM and quasi-FMDM models in model fit is not surprising because the generalized $R^{2}$ is based on prediction errors and the two models have identical instruments. Because the three DM models are not nested, we used the Rivers-Vuong (Rivers and Vuong 2002) non-nested model comparison test to examine whether the difference in model fit is statistically significant. Table 5 reports the test results. According to the test, the improvement in the generalized $R^{2}$ of the FMDM and quasi-FMDM models over the conventional DM model is statistically significant at the $1 \%$ level, while the FMDM is statistically indistinguishable from its approximate version in terms of goodness of fit.

Revisiting table 4, the coefficients for seven conventional DM model attributes and six FMDM and quasi-FMDM model attributes are statistically significant at the $1 \%$ level. Consistent with the a priori expectation that the degree of product substitution increases with closeness in the attribute space, the coefficients for major product, product category, energy category, and flavor are positive across the three models. For the conventional DM and quasi-FMDM models, the negative and significant coefficients on brand family and name brand suggest that two products being in the same brand family or being name brands decreases substitutability. Of note, the coefficients on the attribute variables in the FMDM model are not directly comparable with those of the conventional DM and quasi-FMDM models in sign and magnitude due to substantive differences in model specification and formulation of elasticities. Because budget shares appear on both sides of the demand equation, a negative coefficient in the FMDM model does not necessarily suggest that closeness in the associated attribute reduces the degree of substitution.

In terms of elasticity estimates, the median unconditional own-price elasticity is approximately -1.9 in all three models. Of the 7,211,034 cross-price elasticities in the sample, about one-half of them are negative, indicating that not all products are substitutes. This differs from applications of discrete-choice models that restrict products to be substitutes. The FMDM model has slightly higher median cross-price elasticity than the conventional DM and quasi-FMDM models.

The above comparisons, however, do not give a full account of the differences across DM models. In a market with a large number of products and an assortment of product attributes, small differences in price elasticities may add up to large differences in predicted SSB taxinduced changes in total calories, consumer surplus, and tax revenue. In the next section, we examine this possibility through counterfactual simulations.

\section{Tax Simulations}

Table 6 reports results from a simulation of two hypothetical excise tax scenarios. In the first scenario, a half-cent per-ounce tax is levied on all SSBs with more than $10 \mathrm{kcal} / 8$-ounce serving. In the second scenario, a 0.04-cent per kcal tax-equivalent to a half-cent tax per ounce of regular Coke ${ }^{12}$ - is imposed on SSB products. In both cases, we assumed the 
excise tax is passed one-for-one to retail prices. Using the estimated unconditional elasticities, we predicted the outcomes for all markets and time periods.

In the first panel of table 6, the first-order effect measures the direct effect of an SSB tax on group price index $p_{b h t}$ holding budget shares fixed at the pretax levels. The second-order effect reflects the indirect effect of changing budget shares on the group price index $p_{b h t}$ (see equation [6] and related discussion). On average, the first-order effect of a half-cent per ounce SSB tax is to raise $p_{b h t}$ by $7.56 \%$ compared with $7.25 \%$ from a 0.04 -cent per kcal SSB tax. The second-order effect is mostly statistically insignificant and trivial in magnitude. This is consistent with results in Green and Alston (1990) and Alston, Foster, and Green (1994) showing that this second-order effect is quantitatively unimportant in calculating elasticities.

The second panel of table 6 presents simulated reductions in beverage calories following an SSB tax. Two noteworthy patterns emerge from these results. First, within each DM model, the ounce-based tax always produces less calorie reduction than the calorie-based tax even though the calorie-based tax is less expensive in terms of its impact on group price. Second, the magnitude of reduction continues to decline as we move from the conventional DM model to the quasi-FMDM model and then to the FMDM model. These occur because the FMDM model estimates a higher degree of product substitution than the conventional DM and quasi-FMDM models. As substitutability increases, consumers are more likely to offset the impact of an SSB tax by switching to untaxed caloric beverages (e.g., 100\% juice) and SSBs that have lower relative prices than other SSBs. A calorie-based SSB tax is better able to reduce this slippage effect than an ounce-based one.

We calculated the CV associated with each SSB tax strategy as follows:

$$
C V=\exp \left\{a_{0}+a_{b} \ln p_{b}^{*}+a_{o} \ln p_{o}^{*}+0.5 r_{b b}\left(\ln p_{b}^{*}\right)^{2}+r_{b o} \ln p_{b}^{*} \ln p_{o}^{*}+0.5 r_{o o}\left(\ln p_{o}^{*}\right)^{2}+u b_{0}\left(p_{b}^{*}\right)^{b_{b}}\left(p_{o}^{*}\right)^{b_{o}}\right\}-y,
$$

where the market and time subscripts are suppressed to simplify notation, the superscript * denotes posttax price level. ${ }^{13}$ Mean per capita CV estimates and predicted tax burdens are reported in the third panels of table 6 . Consistent with the above discussion, the tax burden is the highest in the FMDM model due to a smaller predicted reduction in SSB demand; and a calorie-based SSB tax implies a lower CV and tax burden than an ounce-based one within each DM model. Finally, the FMDM model predicts that a calorie-based SSB tax would cost $\$ 1.40$ less in consumer surplus loss per 3,500 kcal reduced than an ounce-based one. In contrast, the difference in $\mathrm{CV}$ predicted by the conventional DM model between the two tax scenarios is $\$ 0.42$ per 3,500 kcal reduced. The quasi-FMDM model, despite its equivalence with the FMDM in the goodness of fit measure, predicts a lower estimate, at $\$ 0.87$ per 3,500 kcal reduced, of the difference in CV between the two taxes.

\footnotetext{
${ }^{12}$ There are $100 \mathrm{kcal}$ per 8 ounces of regular Coke.

${ }^{13}$ The term $u b_{0}$ was recovered by solving this equation consisting of pretax prices:

$\ln y=\left\{a_{0}+a_{b} \ln p_{b}+a_{o} \ln p_{o}+0.5 r_{b b}\left(\ln p_{b}\right)^{2}+r_{b o} \ln p_{b} \ln p_{o}+0.5 r_{o o}\left(\ln p_{o}\right)^{2}+u b_{0}\left(p_{b}\right)^{b_{b}}\left(p_{o}\right)^{b_{o}}\right\}$ (See equation $\{4\}$ of Deaton and Muellbauer 1980).
} 


\section{CONCLUSION}

U.S. policy makers continue to propose SSB tax legislation as a means to curb obesity and raise government revenue. When the main objective of an SSB tax is to improve public health, we show that a calorie-based SSB tax is more efficient than an ounce-based SSB tax in the sense that the former is able to achieve a given calorie reduction target with smaller loss in consumer surplus. A food or beverage product is composed of a number of nutrients and characteristics, the levels of which may vary widely from one product to another. An optimal obesity-aimed food or beverage tax policy should directly target the ingredient(s) or nutrient(s) of concern. Because almost all calories in an SSB product come from added sugars, a calorie-based SSB tax is equivalent to a tax on sugars.

We proposed a new product-level demand model, called the FMDM model, to quantify the efficiency gain from substituting a calorie-based SSB tax for an ounce-based one. Like the conventional DM model, the FMDM model is able to handle hundreds of products. However, the new model outperforms the conventional DM model in model fit and in the economic significance of its predictions.

In the empirical analysis of New York supermarket beverage sales, the FMDM model estimated product-level demand for 178 products representing more than $90 \%$ of total beverage sales in Nielsen ScanTrack scanner data. For every 3,500 beverage calories reduced, the estimated consumer surplus loss due to a calorie-based tax is $\$ 1.40$ lower than the loss induced by an ounce-based tax. A 0.04-cent per kcal SSB tax is predicted to reduce beverage energy from ScanTrack supermarkets by 9.3\%, compared with $8.6 \%$ from a halfcent per ounce tax. Applying this percentage change to beverages obtained from all sources, we calculated that a 0.04 -cent per kcal tax on SSBs will reduce total beverage energy by about 5,800 kcal per capita per year. ${ }^{14}$ Compared with an ounce-based SSB tax that also achieves a 5,800 kcal reduction in beverage energy, the 0.04-cent per kcal SSB tax is estimated to save $\$ 2.35$ per capita or $\$ 736$ million for the U.S. population in consumer surplus per year. Although these numbers may seem trivial relative to the size of the U.S food market, to put them into perspective, the savings is equal to a nonnegligible $15.4 \%$ of the projected tax revenue from a per-calorie SSB tax.

We have assumed that an SSB tax is passed one for one to retail price. However, Bonnet and Réquillart (2013) provided evidence that the French beverage industry over-shifts cost changes to retail price. If this is also the case for the United States, our simulated beverage calorie reduction will be underestimated. We also assumed that the per-calorie and perounce taxes are excise taxes included in the shelf prices. Zheng, McLaughlin, and Kaiser (2013) demonstrated how consumers' ignorance about the level of sales taxes, which are not posted on the shelf, could cause them to purchase more than they otherwise would if fully informed.

The cross-price effects in DM models hinge on the attribute variables. When the researcher omits some attributes, the estimated cross-price effects may be biased. If the omitted-

${ }^{14}$ Total energy intake from regular CSD, sports and energy drinks, fruit drinks, and $100 \%$ juice is about $63,000 \mathrm{kcal}$ per capita per year for people ages 5 and above based on the 2007-2008 National Health and Nutrition Examination Survey. 
variable problem creates a downward bias on the cross-price elasticities in our application, the reported calorie reduction may be overestimated and savings from a per-calorie tax underestimated.

As SSBs become more expensive, consumers might substitute foods and alcoholic beverages. In a field experiment involving 113 households from a U.S. supermarket chain, Wansink et al. (2012) reported increases in beer purchase after a 10\% tax was imposed on SSBs and other foods with little nutritional value. Because we did not have ScanTrack data on fluid milk, alcoholic beverage, and food sales, we were unable to estimate demand for these products and simulate the effects of different SSB taxes on food and alcohol consumption.

Finally, it is important to recognize that our study does not assess the practicality of levying an ounce-based tax versus a calorie-based one. An ounce-based SSB tax is likely to be easier to implement than a more sophisticated calorie-based tax when there is a large variety of SSB products in terms of caloric content. However, it is precisely when there is a large variation in caloric content across products that a calorie-based tax is expected to be more efficient in terms of consumer surplus saved. Moreover, a calorie-based tax may motivate beverage manufacturers to reformulate SSB products to contain less sugar, while an ouncebased tax may be less likely to have such an effect on product formulation. Therefore, one cannot make a final determination on the least expensive form of tax until information on these aspects of the issue becomes available.

\section{Supplementary Material}

Refer to Web version on PubMed Central for supplementary material.

\section{Acknowledgments}

Chen Zhen is a Research Economist in the Food and Nutrition Policy Research Program at Research Triangle Institute (RTI), NC. Ian Brissette is a Research Scientist at the New York State (NYS) Department of Health and Director of the Bureau of Chronic Disease Evaluation and Research. Ryan Ruff is an Assistant Professor in the Department of Epidemiology and Health Promotion, New York University College of Dentistry. The research was completed while he was Director of Research \& Evaluation Unit in the Bureau of Chronic Disease Prevention and Tobacco Control at the New York City (NYC) Department of Health and Mental Hygiene. We thank two anonymous reviewers and the editor, Brian Roe, for useful comments and suggestions. We also benefited from discussions with Tamara Dumanovsky, Ann Lowenfels, Anne Sperling and Alessandro Bonnano. This research was supported by grants from the Robert Wood Johnson Foundation's Healthy Eating Research (66971), Centers for Disease Control and Prevention (CDC) (3U58DP001963-01S4) and the National Heart, Lung, and Blood Institute, National Institute of Health (1R21HL108121). The findings and conclusions in this article are those of the authors and do not represent the views of the NYC and NYS Departments of health, or CDC.

\section{REFERENCES}

Alston JM, Foster KA, Green RD. Estimating Elasticities with the Linear Approximate Almost Ideal Demand System: Some Monte Carlo Results. Review of Economics and Statistics. 1994; 76:351356.

Bonanno A. Functional Foods as Differentiated Products: The Italian Yogurt Market. European Review of Agricultural Economics. 2013; 40:45-71.

Bonnet C, Réquillart V. Impact of Cost Shocks on Consumer Prices in Vertically-Related Markets: The Case of the French Soft Drink Market. American Journal of Agricultural Economics. 2013; 95:1088-1108. 
Bridging the Gap. State Sales Taxes on Soda, Bottled Water, and Snack Foods. 2014. Available at: http://www.bridgingthegapresearch.org/research/sodasnack_taxes/ Downloaded on April 22, 2014

Deaton AS, Muellbauer J. An Almost Ideal Demand System. American Economic Review. 1980; 70:312-326.

Dharmasena S, Capps O Jr. Intended and Unintended Consequences of a Proposed National Tax on Sugar-Sweetened Beverages to Combat the U.S. Obesity Problem. Health Economics. 2012; 21:669-694. [PubMed: 21538676]

Dubé J-P, Fox JT, Su C-L. Improving the Numerical Performance of Static and Dynamic Aggregate Discrete Choice Random Coefficients Demand Estimation. Econometrica. 2012; 80:2231-2267.

Durbin J. Error in Variables. Review of International Statistical Institute. 1954; 22:23-32.

Ellison SF, Cockburn I, Griliches Z, Hausman J. Characteristics of Demand for Pharmaceutical Products: An Examination of Four Cephalosporins. Rand Journal of Economics. 1997; 28:426-446. [PubMed: 11794359]

Finkelstein EA, Zhen C, Bilger M, Nonnemaker J, Farooqui AM, Todd JE. Implications of a SugarSweetened Beverage (SSB) Tax When Substitutions to Non-Beverage Items Are Considered. Journal of Health Economics. 2013; 32:219-239. [PubMed: 23202266]

Green R, Alston JM. Elasticities in AIDS Models. American Journal of Agricultural Economics. 1990; 72:442-445.

Fletcher JM, Frisvold D, Tefft N. The Effects of Soft Drink Taxes on Child and Adolescent Consumption and Weight Outcomes. Journal of Public Economics. 2010; 94:967-974.

Hausman J. Specification Tests in Econometrics. Econometrica. 1978; 46:1251-1271.

Huang R, Kiesel K. Does Limited Access at School Result in Compensation at Home? The Effect of Soft Drink Bans in Schools on Purchase Patterns Outside of Schools. European Review of Agricultural Economics. 2012; 39:797-820.

Knittel CR, Metaxoglou K. Estimation of Random Coefficient Demand Models: Two Empiricists' Perspective. Review of Economics and Statistics. 2014; 96:34-59.

LaFrance JT, Hanemann WM. The Dual Structure of Incomplete Demand Systems. American Journal of Agricultural Economics. 1989; 71:262-274.

LaFrance JT. When is Expenditure 'Exogenous' in Separable Demand Models? Western Journal of Agricultural Economics. 1991; 16:49-62.

Lewbel A, Pendakur K. Tricks with Hicks: The EASI Demand System. American Economic Review. 2009; 99:827-863.

Lin B-H, Smith TA, Lee J-Y, Hall KD. Measuring Weight Outcomes for Obesity Intervention Strategies: The Case of a Sugar-Sweetened Beverage Tax. Economics and Human Biology. 2011; 9:329-341. [PubMed: 21940223]

Moschini G. Units of Measurement and the Stone Index in Demand System Estimation. American Journal of Agricultural Economics. 1995; 77:63-68.

National Cancer Institute. Table 1a. Mean Intake of Energy and Percentage Contribution of Various Foods Among US Population, by Age, NHANES 2005-06. 2010. Available at: http:// riskfactor.cancer.gov/diet/foodsources/energy/table1a.html. Accessed February 13, 2013

Nevo A. Measuring Market Power in the Ready-to-Eat Cereal Industry. Econometrica. 2001; 69:307342.

New York City Department of Health. Food and Drink at Meetings and Events: What to Serve.. 2013. Available at: http://www.nyc.gov/html/doh/downloads/pdf/cdp/cdp-pan-hwp-nutritionstandards.pdf. Accessed April 18, 2013

Ogden, CL.; Carroll, MD.; Kit, BK.; Flegal, KM. NCHS Data Brief, no 82. National Center for Health Statistics; Hyattsville, MD: 2012. Prevalence of Obesity in the United States, 2009-2010..

Pesaran MH, Smith RJ. A Generalized $\mathrm{R}^{2}$ Criterion for Regression Models Estimated by the Instrumental Variables Method. Econometrica. 1994; 62:705-710.

Pinkse J, Slade ME, Brett C. Spatial Price Competition: A Semiparametric Approach. Econometrica. 2002; 70:1111-1153.

Pinkse J, Slade ME. Mergers, Brand Competition, and the Price of a Pint. European Economic Review. 2004; 48:617-643. 
Pofahl GM, Richards TJ. Valuation of New Products in Attribute Space. American Journal of Agricultural Economics. 2009; 91:402-415.

Rivers D, Vuong Q. Model Selection Tests for Nonlinear Dynamic Models. Econometrics Journal. 2002; 5:1-39.

Rojas C, Peterson EB. Demand for Differentiated Products: Price and Advertising Evidence from the U.S. Beer Market. International Journal of Industrial Organization. 2008; 26:288-307.

Rudd Center for Food Policy \& Obesity. Map of Excise and Sales Tax Legislation 2013. 2013. Available at: http://www.yaleruddcenter.org/resources/upload/docs/what/policy/ssbtaxes/ SSB_Sales_and_Excise_Tax_Legislation_2013/ SSB_Sales_and_Excise_Tax_Legislation_2013.htm. Accessed on March 7, 2013

Sam AG, Zheng Y. Semiparametric Estimation of Consumer Demand Systems with Micro Data. American Journal of Agricultural Economics. 2010; 92:246-257.

Schulze MB, Manson JE, Ludwig DS, Colditz GA, Stampfer MJ, Willett WC, Hu FB. Sugarsweetened Beverages, Weight Gain, and Incidence of Type 2 Diabetes in Young and Middle-aged Women. Journal of the American Medical Association. 2004; 292:927-934. [PubMed: 15328324]

Wansink, B.; Hanks, AS.; Just, DR.; Cawley, J.; Kaiser, HM.; Sobal, J.; Wethington, E.; Schulze, WD. Cornell University; 2012. From Coke to Coors: A Field Study of a Sugar-Sweetened Beverage Tax and Its Unintended Consequences.. Working paper

Wu D. Alternative Tests of Independence Between Stochastic Regressors and Disturbances. Econometrica. 1973; 41:733-750.

Yen ST, Lin B-H, Smallwood DM. Quasi- and Simulated-Likelihood Approaches to Censored Demand Systems: Food Consumption by Food Stamp Recipients in the United States. American Journal of Agricultural Economics. 2003; 85:458-478.

Zhen C, Wohlgenant MK, Karns S, Kaufman P. Habit Formation and Demand for Sugar-Sweetened Beverages. American Journal of Agricultural Economics. 2011; 93:175-193.

Zhen C, Finkelstein EA, Nonnemaker J, Karns S, Todd JE. Predicting the Effects of Sugar-Sweetened Beverage Taxes on Food and Beverage Demand in a Large Demand System. American Journal of Agricultural Economics. 2014; 96:1-25. [PubMed: 24839299]

Zheng Y, McLaughlin EW, Kaiser HM. Taxing Food and Beverages: Theory, Evidence, and Policy. American Journal of Agricultural Economics. 2013; 95:705-723. 


\section{Table 1}

Average Annual per Capita Purchases, 2007-2011

\begin{tabular}{llll}
\hline & \multicolumn{3}{c}{ Per capita } \\
\cline { 2 - 4 } & Volume (oz/year) & Energy (kcal/year) & Expenditure (\$/year) \\
\hline Regular CSD & 870 & 10,969 & 20.08 \\
Diet CSD & 653 & 0 & 15.43 \\
Sports/energy drinks & 106 & 654 & 4.44 \\
100\% juice & 435 & 6,142 & 21.17 \\
Fruit drinks & 339 & 3,538 & 12.16 \\
Bottled water & 840 & 0 & 10.04 \\
Total & 3,243 & 21,303 & 83.31 \\
\hline
\end{tabular}

Notes:CSD stands for carbonated soft drink. These data represent sales of the 178 brands that are included in the DM models, which account for 95\%, 92\%, and 94\% of ScanTrack total nonalcoholic beverage sales in volume, dollars, and energy, respectively. The ScanTrack data we have exclude milk, bottled tea and coffee, and soft drink powder and do not include sales at restaurants, convenience stores, drug stores, and mass merchandisers. Expenditures were deflated by the consumer price index using the 2007-2011 average as the base. 


\section{Table 2}

First-Stage Incomplete AIDS Estimates

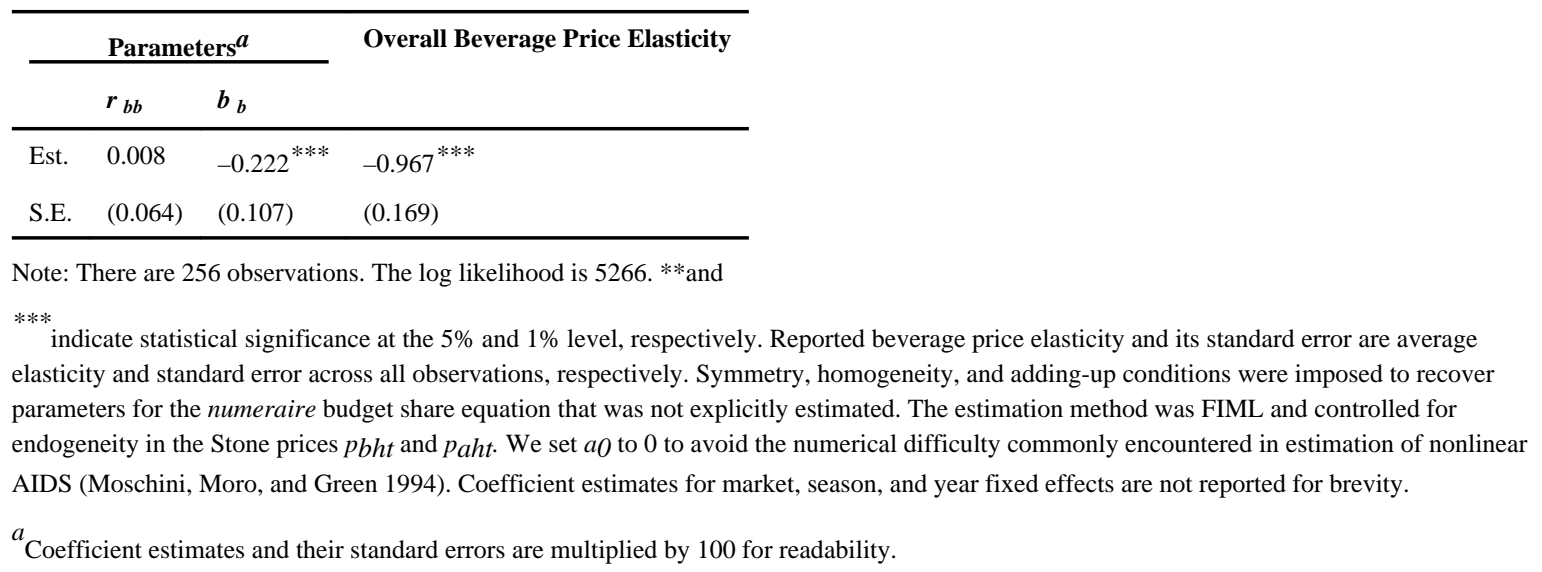




\section{Table 4}

DM Demand Model Results

\begin{tabular}{lccc}
\hline \multirow{2}{*}{ Product Attributes } & \multicolumn{3}{c}{ Cross-Price Coefficient Est. $\left(\boldsymbol{d}_{\boldsymbol{m}}\right)$} \\
\cline { 2 - 4 } & Conventional DM $\boldsymbol{a}$ & Quasi-FMDM & FMDM \\
\hline brand family & $-0.088^{* * *}(0.022)$ & $-0.222^{* * *}(0.048)$ & $-0.369^{* * *}(0.076)$ \\
name brand & $-0.294^{* * *}(0.091)$ & $-0.728^{* * *}(0.115)$ & $-0.806^{* * *}(0.119)$ \\
major product & $0.679^{* * *}(0.113)$ & $0.251^{* * *}(0.101)$ & $0.167^{* *}(0.098)$ \\
product category & $0.309^{* * *}(0.039)$ & $0.473^{* * *}(0.044)$ & $0.560^{* * *}(0.054)$ \\
energy category & $0.358^{* * *}(0.081)$ & $0.869^{* * *}(0.068)$ & $1.113^{* * *}(0.084)$ \\
caffeine & $0.896^{* * *}(0.177)$ & $-0.126(0.089)$ & $-0.641^{* * * *}(0.102)$ \\
flavor & $0.291^{* * *}(0.038)$ & $0.774^{* * *}(0.051)$ & $0.967^{* * *}(0.062)$ \\
Median unconditional own-price elasticity & -1.917 & -1.947 & -1.917 \\
Median unconditional cross-price elasticity & $-7.0 \mathrm{E}-04$ & $-8.0 \mathrm{E}-05$ & $4.2 \mathrm{E}-05$ \\
$\%$ positive own-price elasticities & $4.3 \%$ & $3.2 \%$ & $3.5 \%$ \\
$\%$ negative crossprice elasticities & $53.1 \%$ & $50.9 \%$ & $49.1 \%$ \\
Number of parameters $b$ & 720 & 720 & 720 \\
Generalized $\mathrm{R}^{2}$ & 0.481 & 0.493 & 0.493 \\
\hline
\end{tabular}

Note:

There are 43,087 observations.

**

indicate statistical significance at the $10 \%, 5 \%$, and $1 \%$ level, respectively. Standard errors are in parentheses. The generalized R2 is calculated based on Pesaran and Smith (1994).

*** indicate statistical significance at the $10 \%, 5 \%$, and $1 \%$ level, respectively. Standard errors are in parentheses. The generalized R2 is calculated based on Pesaran and Smith (1994).

${ }^{a}$ Coefficient estimates and standard errors for the conventional DM model are multiplied by 100 for readability.

$b_{\text {There are }} 178$ product-specific own-price coefficients, 178 product-specific group expenditure coefficients, 178 product-specific temperature coefficients, 178 product-specific trend coefficients, 7 discrete-attribute coefficients, and an intercept. The within-transformation removes productmarket specific fixed effects prior to estimation. 


\section{Table 5}

Rivers-Vuong Test of Non-nested Models

\begin{tabular}{ll}
\hline Model A vs. Model B & Test Statistic \\
\hline Conventional DM vs. Quasi-FMDM & $3.85^{* * *}$ \\
Conventional DM vs. FMDM & $398^{* * *}$ \\
Quasi-FMDM vs. FMDM & 0.15 \\
\hline
\end{tabular}

Note:

indicates significance at the $1 \%$ level. Under the null hypothesis of equivalence between Models A and B, the Rivers-Vuong test statistic is standard normally distributed. A positive (negative) statistically significant test statistic suggests that Model B (A) is preferred to Model A (B). 
Table 6

Simulated Per Capita Effects of SSB Taxes on Demand and Welfare

\begin{tabular}{|c|c|c|c|}
\hline Conventional DM & & Quasi-FMDM & FMDM \\
\hline \multicolumn{4}{|c|}{$\%$ change in beverage group price, ounce-based tax } \\
\hline First-order effect ${ }^{a}$ & $7.56 \%$ & $7.56 \%$ & $7.56 \%$ \\
\hline Second-order effect & $-0.04 \%(0.4)$ & $0.06 \%(0.6)$ & $-0.13 \%(1.3)$ \\
\hline \multicolumn{4}{|c|}{$\%$ change in beverage group price, calorie-based tax } \\
\hline First-order effect ${ }^{a}$ & $7.25 \%$ & $7.25 \%$ & $7.25 \%$ \\
\hline Second-order effect & $-0.12 \%(0.9)$ & $0.00 \%(0.0)$ & $-0.19 \%(2.0)$ \\
\hline \multicolumn{4}{|c|}{ Reduction in energy intake from beverages ( $\mathrm{kcal} / \mathrm{year}$ ) } \\
\hline Ounce-based tax & $\begin{array}{l}3,060 \\
(53.8)\end{array}$ & $\begin{array}{l}2,778 \\
(63.8)\end{array}$ & $\begin{array}{l}1,836 \\
(57.4)\end{array}$ \\
\hline Calorie-based tax & $\begin{array}{l}3,090 \\
(53.9)\end{array}$ & $\begin{array}{l}2,967 \\
(62.0)\end{array}$ & $\begin{array}{l}1,976 \\
(58.1)\end{array}$ \\
\hline \multicolumn{4}{|c|}{ Compensating variation $(\$ /$ year $)$} \\
\hline Ounce-based tax & $6.07(52.1)$ & $6.15(58.7)$ & $6.00(56.9)$ \\
\hline Calorie-based tax & $5.77(51.3)$ & $5.86(58.7)$ & $5.71(56.6)$ \\
\hline \multicolumn{4}{|l|}{ Tax burden $(\$ /$ year $)$} \\
\hline Ounce-based tax & $4.83(34.8)$ & $5.00(36.2)$ & $5.39(35.9)$ \\
\hline Calorie-based tax & $4.65(34.3)$ & $4.74(36.5)$ & $5.13(36.1)$ \\
\hline \multicolumn{4}{|c|}{ Difference in CV between calorie- and ounce-based taxes per 3,500 kcal reduced (\$) } \\
\hline & $0.4158(4.2)$ & $0.8701(4.4)$ & $1.4034(2.5)$ \\
\hline
\end{tabular}

Notes:

Results are for the 178 products included in the demand models. The simulated effects and the associated $t$ statistics (in parentheses) are averages over all markets and time periods. The standard errors were generated by taking 500 random draws from a multivariate normal distribution with the mean vector and variance-covariance matrix set to the estimated values of the first- and second-stage demand models.

${ }^{a}$ The first-order effect is deterministic and calculated using baseline budget shares. 